\title{
Historia y sacrificio. El acceso al fenómeno religioso en el pensamiento de Jan Patočka
}

\section{History and sacrifice. Access to the religious phenomenon in Jan Patočka's thought}

\author{
ÁNGEL E. GARRIDO-MATURANO \\ Conicet - Universidad Católica de Santa Fe, Argentina
}

Recibido: 11-05-2010 Aprobado definitivamente: 28-05-2010

\begin{abstract}
RESUMEN
El artículo analiza la significación del pensamiento de J. Patočka para un acceso no confesional al fenómeno religioso. El análisis persigue dos objetivos. Primero determinar en qué medida los fundamentos de su filosofía de la historia implican una conmoción del orden fenoménico que abre el pensamiento hacia el Misterio que trasciende pero, a la vez, posibilita la historia humana. Segundo, explicitar el sacrificio como el medio por excelencia a través del cual el hombre en la era nihilista puede religarse con el llamado de ese Misterio trascendente a realizar la infinita riqueza del ser y mantener viva la historia como historia con sentido.
\end{abstract}

\section{PALABRAS CLAVE \\ HISTORIA, SACRIFICIO, SENTIDO, LO DIVINO.}

\begin{abstract}
The paper analyzes the significance of J. Patočka's thought for a non confessional access to the religious phenomenon. The analysis pursues two objectives. Firstly, to determine to what extent the foundations of his philosophy of history imply a commotion of the phenomenal order that opens the thought to the Mystery that transcends, but, at the same time, makes human history a reality. Secondly, to explicit sacrifice as the medium par excellence through which the man in the nihilistic era can connect (re-ligare) himself with the call from this transcendent Mystery to fulfil the infinite richness of being and maintaining history alive as well as meaningful.
\end{abstract}

KEYWORDS

HISTORY, SACRIFICE, MEANING, THE DIVINE.

(C) Contrastes. Revista Internacional de Filosofía, vol. XVI (2011), pp. 173-191. ISSN: 1136-4076 Departamento de Filosofía, Universidad de Málaga, Facultad de Filosofía y Letras

Campus de Teatinos, E-29071 Málaga (España) 


\section{INTRODUCCIÓN}

Ciertamente el Pensamiento del filósofo checo Jan Patočka puede ser caracterizado como una más de las numerosas "herejías", esto es, como uno más de los numerosos desarrollos personales a los que dio lugar el empleo de la fenomenología husserliana como método. Puede decirse, además, con la misma certeza, que la otra gran fuente de su obra ha sido la filosofía heideggeriana, en particular la cuestión de la diferencia ontológica y el problema que representa para nuestra época histórica el olvido del ser y el imperio de la concepción científico-técnica del ente. Puede decirse, finalmente, que la entera filosofía de Patočka no consiste sino en una hermenéutica original, pero estrictamente filosófica del pensamiento de sus dos fuentes fenomenológicas fundamentales. Como afirma Filip Karfík, la entera filosofía patočkiana resulta del esfuerzo hermenéutico constante por "adaptar y readaptar las concepciones de sus dos grandes maestros en fenomenología, agregándole a ellas sin cesar sus propias reflexiones y análisis". ${ }^{1}$ Tales análisis, como también indica atinadamente el intérprete, están puestos al servicio de las dos cuestiones más originales de su pensamiento, a saber, proponer una interpretación filosófica de lo que Patočka experimenta como crisis de la humanidad moderna, pero también sentar las condiciones de posibilidad que permitan al hombre superar activamente este estado de crisis. ${ }^{2}$ Ahora bien, ¿en qué medida puede, entonces, sugerirse que constituye un acceso (y, además, un modo esencial de acceso) al fenómeno religioso un pensamiento, cuyas fuentes son en esencia fenomenológicas, que se reconoce a sí mismo como una interpretación puramente filosófica de esas fuentes y cuyas preocupaciones fundamentales atañen básicamente a la filosofía de la historia? ${ }^{3}$ Esta pregunta, que a primera vista pudiera resultar

1 Filip Karfík, "La philosophie de l'histoire et le problème de l'âge technique chez Jan Patočka", en: Études Phénoménologiques", Tome XV, Nos 29-30 (1999), pp. 5-28 ; aquí: p. 5.

2 Cf. ibid.

3 La importancia de la filosofía de la historia en el corpus patočkiano es decisiva. De hecho numerosos de los ensayos publicados de Patočka han estado destinados desde sus primeras hasta sus últimas obras a cuestiones relativas a la filosofía de la historia, desembocando en uno de sus textos fundamentales: los Ensayos heréticos sobre filosofía de la historia. Asimismo, en su obra no publicada, que se conservó en el llamado legado de Strahov, podemos distinguir dos grandes proyectos inconclusos. Un libro que tendría por tema central la filosofía trascendental de la subjetividad y el análisis de la correspondiente objetividad del mundo, cuyo título presuntamente sería Interioridad y mundo (Inneres und Welt), y otro que sería justamente una filosofía de la historia ( $c f$. Filip Karfík, "Jan Patočkas Strahov-Nachlass und sein unvollendetes opus grande", en: Jan Patočka, Andere Wege in die Moderne, Hrsg. L. Hagedorn, Würzburg: Königshausen \& Neumann, 2006, pp. 39-45). El propio Patočka, en la que presumiblemente sería la introducción a este segundo gran proyecto suyo, afirma que "está convencido de que la filosofía de la historia es una necesaria e ineludible tarea del espíritu humano y que junto con la historia 
paradójica, determina el tema y la cuestión que mueve las reflexiones que han de seguir. Ellas se guían por la siguiente sospecha: el vínculo existente entre la concepción patočkiana del sentido de la historia y el sacrificio como instancia que, para el autor, consuma la existencia humana, abre, en un modo que será por cierto necesario explicitar, un acceso no confesional, que, por ser tal, convoca a todo hombre qua hombre, independientemente de cualquier revelación determinada o fe positiva, a una relación religiosa. Se trata de una relación que, aunque desmitologizada y prescindente de cualquier afirmación sobrenatural, podemos en verdad llamar religiosa, en tanto re-liga o restablece el lazo entre el hombre y lo divino actuante a través de la existencia humana en la historia. Dicho de modo tal vez más sencillo, dos son las vías a través de las cuales en la filosofía de Patočka se produce una conmoción del orden fenoménico que abre el pensamiento a la cuestión de lo divino: la vía del sentido de la historia y la vía del sacrificio. Me guía, pues, la sospecha de que la comprensión vivida del vínculo entre estas dos vías implica un acceso hermenéutico-fenomenológico genuino -ni único, ni excluyente, pero, por cierto, tampoco excluible-al fenómeno religioso. La idea de "acceso hermenéutico-fenomenológico" significa aquí un sendero que se abre exclusivamente al pensamiento, al margen de toda fe positiva, y que es hermenéutico y fenomenológico en cuanto resulta de una interpretación del sentido, esto es, de aquello sobre la base de lo cual es posible la historia como ámbito de consumación de la existencia humana, tal cual esta existencia originaria y genuinamente se manifiesta.

Con lo antedicho quedan sentadas las bases tanto de los objetivos cuanto del método del presente trabajo. Dos son, entonces, las metas a seguir. En primer lugar, determinar en qué medida los fundamentos de la filosofía de la historia de Patočka implican un elemento suprahistórico - que podríamos llamar Dios o lo divino- que se testimonia en la existencia como el sentirse llamado a advenir hacia configuraciones de sentido siempre nuevas $\mathrm{y}$, de ese como, a existir históricamente. En segundo lugar, explicitar cómo y por qué el sacrificio es el medio por excelencia a través del cual el hombre, en la era del sinsentido nihilista, se relaciona pasiva y activamente con lo divino $\mathrm{y}$, haciéndolo, mantiene viva la historia como la historia de la búsqueda humana de sentido. El logro de estas metas debe, además, dejar en claro que la relación religiosa abierta por el pensamiento de Patočka no implica ninguna "doctrina" fija ni puede realizarse de manera definitiva, sino que, precisamente en tanto

en el sentido propiamente dicho debe tener lugar obligatoriamente en el pensamiento históricofilosófico" (Jan Patočka, "Einleitung. Geschichte als geistige Lebensform”, en: ibid., p. 65). En líneas generales la filosofía de la historia es concebida por Patočka como una interpretación del sentido de los hechos históricos y de los procesos causales esenciales que generan las distintas épocas históricas, pero que no se dejan reconducir por completo a la noción meramente fáctica de causalidad (cf. ibid., p. 66). 
histórica, se trata de un acontecimiento dinámico y cambiante que, en última esencia, podría caracterizarse, usando la expresión del propio pensador checo, como "existencia en la verdad". Desde el punto de vista metodológico las observaciones que siguen admiten ser consideradas como una hermenéutica constructiva que procura articular por vía de una interpretación personal el vínculo entre estos dos ejes temáticos -la cuestión del sentido de la historia y la del sacrificio- en el pensamiento de Patočka, particularmente en sus obras de las décadas del 60 y 70, de modo tal de "dejar ver" a través suyo el peculiar vínculo religioso al que se abre la filosofía del autor.

\section{FILOSOFÍA DE LA HISTORIA}

\section{II.1 EL ORIGEN DE LA HISTORIA}

Preguntarse por el origen de la historia equivale a preguntarse por aquella experiencia del tiempo que hace que éste sea vivido no al modo en que lo entendía la física newtoniana, esto es, no como la mera sucesión continua de instantes homogéneos en la que todo sucede y que no reconoce dimensiones temporales, sino como la interpenetración de los horizontes de presente, pasado y futuro. Ello ocurre cuando un existente específicamente humano vive su presente no como un mero ahora determinado por el ahora precedente, sino como aquel lapso extático que, a partir de su estar ya siempre pro-yectado hacia una posibilidad de ser, niega el pasado como algo definitivo y determinante y lo refigura o recupera precisamente desde las posibilidades hacia las cuales adviene. Por ello con razón afirma Patočka ${ }^{4}$ que, para que haya tiempo histórico, no basta la mera sucesión de la conciencia, esto es, su transcurso como un objeto más del mundo, ni la mera conciencia de la sucesión. Ninguna de las dos características son específicamente humanas, sino que tanto la una como la otra conciernen igualmente a los animales, cuya vida es sucesiva y que perciben la sucesión, pero que, sin embargo, no tienen existencia histórica, en cuanto se hayan presos en los límites de un presente exiguo. El tiempo histórico, por el contrario, exige ser con-formado desde un presente extático que se ex-tiende hacia su pasado, negando que sea un dato definitivo y determinante, y lo reinterpreta a partir de la proyección, asumida por el existente, hacia un cierto advenir. El tiempo histórico es, así, experimentado desde el advenir y, por serlo, es esencialmente creador: "él es la creación de lo nuevo". 5 Ahora bien, para que el advenir

$4 C f$. Jan Patočka, L'art et le temps, trad. (francesa) de E. Abrams, París: P.O.L., 1990, p. 30. Sigla: $A T$.

$5 A T$, p. 31. 
nos permita recuperar el conjunto del pasado humano y actúe como la fuerza motriz que impulsa y renueva en su integridad el presente no sólo de un cierto existente, sino del conjunto de la sociedad, es necesario que dicho advenir no sea un mero advenir parcial, un advenir a una cierta posibilidad particular de uno o un grupo determinado de existentes, sino que es menester que sea lo que Patočka llama un "advenir total". ${ }^{6}$ Por tal ha de entenderse un porvenir que, sin ser un pro-ducto del pasado y de la sucesión continua causada por ese pasado, con-voca a todos aquellos que existen conjuntamente, concierne las distintas dimensiones de su existencia en común y configura aquello hacia lo que se proyectan de un modo integral todos esos hombres que son unos con otros en un mundo en común. Dicho en otros términos, el "advenir total" mienta un sentido nuevo que está ausente en una determinada civilización, pero que la libera del carácter determinístico de su pasado y reorienta por entero el curso del presente de esa civilización.

Ahora bien -y ésta es una cuestión nuclear para nuestra perspectiva de análisis- este "advenir total" no es concebido por Patočka como el resultado de una decisión espontánea, arbitraria y unilateral del hombre. No es tampoco un hecho natural, pues no pertenece al tiempo del mundo como orden sucesivo, sino que debe ser pensado como la respuesta al llamamiento de una "alteridad absoluta". En tal medida el tiempo histórico, "en lo que él tiene propiamente de humano es imposible sin el contacto o, antes bien, el llamado de alguna cosa que se sitúa fuera del contenido de la experiencia actual, es decir, fuera de la sucesión causal que atraviesa la realidad toda"7; pero que, sin embargo, orienta el conjunto de esa misma realidad, toda vez que pone en marcha el "advenir total" al que ella tiende. Por ello mismo puede el filósofo afirmar, sin temor a la paradoja, que "a la conciencia humana del tiempo pertenece esencialmente una relación a alguna cosa que es exterior al mundo temporal en totalidad, como así también al flujo del tiempo". ${ }^{8} \mathrm{La}$ atingencia, el vínculo con esta alteridad, que Patočka no define materialmente, pero que no duda desde el punto de vista formal en calificar como "absoluta", "última" y "determinante", 9 hace posible la experiencia del tiempo de nuestra vida humana social, es decir, la experiencia del tiempo histórico y explica su heterogeneidad. En efecto, el tiempo histórico no fluye homogéneo como el físico o el biológico, sino que es heterogéneo, en tanto distintas son las respuestas a la convocatoria de esta alteridad que nos llama a proyectarnos de modos diversos, esto es, a realizar distintas posibilidades de nuestra existencia social o, dicho de otro modo, a dar

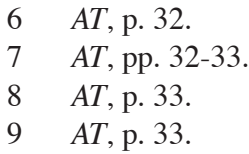


forma a distintos mundos. La historia sería, así, puesta en movimiento por el "advenir total" proyectado por una cierta civilización, pero este mismo advenir sólo sería posible, a su vez, en virtud de un llamamiento desde una alteridad ubicada fuera de la historia. La historia sería, pues, un tiempo correlativo. Sería la gran correlación entre el llamamiento a ser, surgido desde fuera del tiempo y experimentado en el tiempo como el conatus o impulso a ser más de lo que se está determinado a $\operatorname{ser}^{10}$ y realizar, así, históricamente la infinita multidiversidad del ser, y el "advenir total" que responde a ese llamado. Concebida de este modo, la historia misma es una constante "preparación" en el camino hacia esa "alteridad absoluta", hacia esa hora final de la "consumación del tiempo". Si tenemos en cuenta lo antedicho, advertiremos que ya en el origen primigenio, como condición última de posibilidad del tiempo histórico, se abre en el pensamiento de Patočka un camino hacia la trascendencia. En efecto, ¿de qué otro modo pensar esa "alteridad última, absoluta y determinante", cuyo llamado pone en movimiento la entera historia del hombre y que está fuera del flujo temporal, sino como una vocación de lo eterno (el propio Patočka lo denomina la "eternidad real"') y trascendente que nos convoca a dejar acaecer a través de nuestra existencia la infinita riqueza del ser? Perfectamente a este llamado podríamos comprenderlo, dando un paso más allá del propio Patočka, pero evidentemente no contra el sentido de su pensamiento, como la voz silente de Dios pro-moviendo la vida.

Ahora bien, no basta el llamado para poner en movimiento la historia, sino que es preciso, como dijimos, que el hombre responda a ese llamado con un "advenir total", sobre cuya base son comprensibles cada uno de los advenires particulares de cada existente concreto. El hombre mítico tuvo conciencia de esa alteridad absolutamente otra, pero la vida mítica se detuvo en la respuesta a su llamado y, de ese modo, detuvo la correlación. El hombre mítico no comprende "lo otro" como un llamamiento a ser, sino como la sobrepotencia absoluta de uno o más seres superiores a la que debe someterse. Desde entonces vive sujeto a un pasado ya dado, en el que dichas potencias han determinado todo posible advenir. Lo "totalmente otro" adquiere el rango de un poder fatal, que determina el sentido de todo lo que viene después, reduciendo la vida a la mera satisfacción de las necesidades materiales, y el tiempo a una sucesión homogénea donde ya no hay lugar para lo nuevo. El comienzo primordial contiene, pues, la clave de todo lo que habrá de producirse en la realidad, y la existencia a-histórica se limita a una perpetua reiteración de lo ya decidido de una vez y

10 En tal sentido escribe Patocka: "Hay en él [el tiempo histórico AG] momentos de contacto con esta alteridad, última y determinante, que no estará jamás contenida en el tiempo, pero que no por ello deja de estar en condiciones de dar forma y sentido" AT, p. 33.

11 AT, p. 35. 
para siempre. La vida mítica representa, en realidad, una falsa perpetuidad. Es un estado "que no conoce la eternidad real; es una escapatoria ante el llamado del advenir auténtico". ${ }^{12}$ Ella quiere convertir en un hecho dado y definitivo lo que en realidad es un "llamado incondicionado". ${ }^{13}$ De ese modo desoye aquella apelación que, desde lo otro que el tiempo, nos mueve a decidir nuestro advenir y, así, hacer historia. Ella se limita a repetir la representación mítica "ya hecha". Por el contrario, cuando los hombres, llamados desde lo más hondo de su ser a tener que decidir, deciden efectivamente ser sí mismos y proyectan un advenir total y un sentido integral para su mundo en común, entonces puede decirse que esos hombres existen históricamente, pues la historia no es otra cosa que el acontecimiento por el cual el hombre, proyectando su existencia, des-oculta en múltiples modos el sentido del ente en su conjunto. Existir históricamente es negarse a creer que el pasado mítico lo determina todo, que el tiempo es una eterna repetición. Existir históricamente es tomar en serio el tiempo como ámbito de realización del ser. Sólo con la conmoción del sentido mítico comienza la historia. El tiempo histórico es experimentado desde el advenir; y el hombre que lo experimenta, rotas las cadenas que lo sujetaban al pasado determinante, es libre. La historia es el drama de la realización de la libertad humana. ${ }^{14}$

La condición de posibilidad de la historia, a saber, la vivencia del tiempo como tiempo histórico implica, en síntesis, una vía de acceso a lo eterno o divino, que es experimentado bajo la forma del sentir-se llamado por una alteridad absoluta y extratemporal a proyectar en el tiempo libremente nuestro mundo $\mathrm{y}$, de ese modo, dejar que el ser acaezca. Pero, además, puede afirmarse que la respuesta a este llamado es por esencia religiosa en cuanto, para Patočka, implica fe. No fe en ninguna revelación sobrenatural. No una fe positiva, sino fe en la propia libertad. "La concepción [histórica del tiempo AG] en la que prima el advenir sólo es posible bajo las especies de la fe. Ahora la fe es la creencia que ninguna decisión es última e irrevocable. La fe es esencialmente

$12 A T$, p. 35.

13 AT, p. 35.

14 Josef Novák ha destacado también este vínculo íntimo entre historia y libertad en el pensamiento de Patočka, pero, en lugar de acentuar esa libertad como respuesta a un llamado incondicionado a ser, acentúa la angustia que el ejercicio de la libertad también implica. Escribe el erudito: "Así, según Patočka, el hombre existe históricamente en la medida en que él no vegeta simplemente al ritmo de la naturaleza, sino se relaciona a sí mismo y a sus semejantes. Desde que el hombre a-histórico deviene capaz de relacionarse a sí mismo adquiere igualmente la posibilidad de experimentar el vértigo de la libertad en la angustia que lo confronta al abismo más allá del cual su vida permanece suspendida." Josef Novák, "Histoire, historiographie et philosophie de l'histoire", en : Les Cahiers de Philosophie: Jan Patočka. Le soin de l'âme, $\mathrm{N}^{\text {os }}$ 11/12 (invierno 1990/1991), pp. 209-219; aquí: p. 211. 
creencia en la vida." 15 Y la creencia en la vida es esencialmente creencia en la eterna renovación de la vida. No se trata aquí de fe en la vida eterna, sino de fe en la eternidad de la vida. La concepción histórica, que se asienta en el advenir, tiene, pues, fe en el quebrantamiento de lo que es; cree en la posibilidad de la conmoción de lo dado y manifiesto, por lo que (aún) no es. En tal medida la fe puede legítimamente ser definida como creencia en lo invisible. Esto invisible, esto que no es, pero que quiebra la repetición de lo que es y, así, responde con fe al llamado a hacer historia, es la búsqueda de sentido. Pero es esto efectivamente así. ¿Tiene la historia sentido? ¿Cuál es el vínculo entre historia y sentido?

\section{II.2 EL SENTIDO DE LA HISTORIA}

Toda reflexión acerca del sentido de la historia debe definir primero qué entiende por sentido. Jan Patočka en uno de sus Ensayos heréticos sobre la filosofía de la historia ${ }^{16}$ advierte el carácter problemático del concepto. En primer lugar, siguiendo a Frege, Patočka nos recuerda la necesidad lógica de distinguir sentido como manera subjetiva de concebir el objeto de significación en tanto determinación de la objetividad de la cosa. Así, el lucero vespertino y el matutino son dos sentidos diferentes de una misma significación. ${ }^{17}$ De acuerdo con esta diferenciación parecería que la significación queda limitada al dominio de la determinación teorética de la objetividad del objeto, mientras que el sentido es algo más amplio, que concierne también nuestros sentimientos, nuestra voluntad y nuestra manera de actuar. El sentido parecería, así, resultar de una correlación entre lo dado y el modo en que comprendemos lo dado de acuerdo con nuestra propia comprensión de nosotros mismos y del mundo que nos sale al encuentro y en el que desplegamos (no sólo intelectualmente, sino también a través de nuestras acciones, voliciones y emociones) nuestra existencia en su conjunto. Pero la determinación de sentido no sólo exige separarla de la de significación, sino también de la de finalidad. Ni sentido equivale a "para qué" ni la persecución de una finalidad está dotada siempre de sentido. Un sentimiento -el amor- puede tener sentido para nuestra existencia sin estar ligado a una relación instrumental de medios y fines. Y un actuar puede ser conforme a un fin y, sin embargo, no saber cuál es el sentido intrínseco de alcanzar ese fin. Finalmente es menester distinguir sentido de valor. Valores tales como lo bueno o lo bello mientan una cualidad objetiva del ente. Los valores

$15 A T$, p. 35.

16 Jan Patočka, "L'histoire a-t-elle un sens?", en: Ensayos heréticos sobre filosofía de la historia, trad. (francesa) de Erika Abrams, Lagrasse: Verdier, 1981, pp. 65-88. Sigla: EH.

17 Cf. EH, pp. 65-66. 
serían propios de los entes considerados autónomamente. Sin embargo, esos valores, por ejemplo, la belleza de una pintura o lo verdadero de un juicio, sólo tienen sentido para nosotros en la medida en que podamos gestar una conexión comprensible con ellos, es decir, en el marco de nuestra abertura al mundo. Ahora bien, esto no significa que el hombre pueda disponer a voluntad del sentido, sino que él surge de la correlación entre el modo en que el conjunto del ente acaece y el modo en que nuestro "ser-en-el mundo" se abre (o no) a ese acaecimiento. Esto significa que el concepto de sentido es un concepto abierto y dinámico. Esta apertura nos indica que es imposible determinar a priori y de manera universal y necesaria qué es lo que tiene y qué lo que no tiene sentido, y este dinamismo nos advierte que ningún sentido es definitivo, porque el conjunto de lo que es acaece de múltiples maneras, tan múltiples como las formas en que nuestra existencia, vital y cambiante, se abre a ese acaecer. Si tenemos en cuenta lo aquí dicho y las diferenciaciones entre sentido, por un lado, y significación, valor y finalidad, por otro, debemos concluir que es imposible una determinación material definitiva de la noción de sentido. Sólo podemos pensarla en términos formales. Desde este punto de vista la condición de posibilidad del sentido es una correlación entre lo dado y el modo en que cada existente abre el conjunto de su existencia a eso dado. Podemos afirmar que esta correlación tiene sentido pleno cuando lo dado concierne o se vincula con el conjunto de nuestra existencia, de modo tal que ese vínculo es experimentado por el existente como digno de ser vivido y su ruptura como una pérdida, como un vacío, que deja al existente sin nada a lo que re-ferirse y sin razón alguna para existir. Ese vacío es precisamente el vacío de sentido. Además hay que agregar que no es posible concebir el sentido como algo aislado, como propiedad de una singularidad inconexa. Todo sentido individual remite a o se entreteje con el sentido total de la existencia, con aquello que la hace digna de ser vivida de un cierto modo. Cada sentido relativo remite a uno absoluto. "De allí se sigue que la vida humana es imposible sin una confianza ya sea ingenua, ya sea críticamente adquirida, en un sentido absoluto, en un sentido total del universo del ente, de la vida y del devenir"' ${ }^{18}$

Pero no sólo la vida individual, sino también la vida colectiva requieren una confianza, ingenua o crítica, en el sentido integral de esa vida colectiva. Precisamente ese sentido integral es aquello sobre la base de lo cual se configura el "advenir total" de una cierta cultura. Ahora bien, cuando este "advenir total" es una y otra vez asumido críticamente e implica la conmoción del sentido ingenuo dado de modo atemporal, entonces dicha cultura existe históricamente en el significado estricto del término historia. En cambio, cuando el sentido que determina la existencia de una cierta cultura es recibido de manera ingenua y 
se halla fijado desde y por siempre, de modo tal que esta cultura propiamente nunca adviene a nada nuevo, como ocurre en las sociedades míticas, entonces esa sociedad permanece en la prehistoria. Con palabras de Derrida podríamos afirmar que historia "en el auténtico sentido del término sólo podría haberla en el momento en que la experiencia de la responsabilidad se extrae de aquella forma del secreto que recibe el nombre de misterio demoníaco". ${ }^{19} \mathrm{Y}$ ello porque el principal efecto de lo demoníaco "es hacer irresponsable al hombre, dejar perder el sentido o la conciencia de la responsabilidad". ${ }^{20}$ La cuestión del sentido y la de la historia se hallan, pues, intrínseca y no extrínsecamente vinculadas. La pregunta con que cerrábamos el apartado anterior es capciosa. La cuestión del sentido no es una cuestión de la "filosofía de la historia", una pregunta que la filosofía le haría a la historia, sino que es propia de la historia misma, al punto que sólo allí donde el hombre se hace responsable del sentido hay, estrictamente hablando, historia.

\section{II.3 LA HISTORIA DEL SINSENTIDO}

Si se tiene en cuenta lo arriba afirmado, se convendrá que las grandes épocas históricas resultan del modo fundamental en que los hombres han logrado alcanzar en ellas un sentido para su propia existencia conjunta. Pero, ¿cuál es, para Patocka, la relación entre historia y sentido en este momento histórico del Occidente postcristiano?

Para Patočka el cristianismo representó "el impulso hasta el presente más potente, jamás todavía superado, pero jamás tampoco pensado hasta el límite, que hace capaz al hombre de luchar contra la decadencia". ${ }^{21}$ En efecto, el cristianismo es movido por la fe en un sentido total, revelado desde una trascendencia inasible, que rige la entera historia de la humanidad y la encamina hacia el Reino de Dios. La fe no es otra cosa que la confianza en ese sentido ofrecido y su correspondiente aceptación. Sin embargo, no se trata de una aceptación pasiva, ni de la sumisión a un sentido impuesto atemporalmente, sino que, por el contrario, se trata de una conquista activa del sentido: se trata de decir responsablemente "sí" a la interpelación aconteciente de Dios y de determinar toda la existencia en función de su revelación constantemente renovada, que es, a la par, la revelación del verdadero sentido de todo lo que es. Para el cristianismo el sentido de la existencia individual y colectiva no

19 Jacques Derrida, "Den Tod geben. Die Geheimnisse der europäischen Verantwortung", en: Ludger Hagedorn y Hans Reiner Sepp (Hrsg.), Jan Patočka. Texte. Dokumente.Bibliographie, Freiburg/München: Alber, 1999, p. 60.

20 Ibid., p. 59.

21 EH, p. 117. 
proviene, entonces, ya de un poder fatal, sino de un "mysterium tremendum" al cual se halla ligada. Mysterium tremendum, porque el hombre llega a ser la persona única, singular, libre y, por ende, responsable que él en cada caso tiene que ser no por la contemplación de ideas, accesibles a la razón, como en el caso del platonismo, "sino por la relación con un ente supremo, absoluto, inaccesible, que nos tiene en sus manos no exterior, sino interiormente". ${ }^{22}$ Con el cristianismo el yo es por excelencia una individualidad responsable de su destino histórico, porque, puesto en relación con el Amor Infinito, que a cada momento le dona renovadamente la posibilidad de la salvación eterna, él es siempre responsable. Y aquello de lo cual es responsable es su propia salvación o condena eterna. Esta concepción, a saber, que el alma no tiene ya dada su verdad más propia en una idea atemporal, sino que tanto ella como el mundo tienen que redimirse, esto es, tienen que advenir a sí mismos, respondiendo "sí" al don del misterio tremendo y accediendo, así, al sentido de su existencia, es lo que le otorga al cristianismo su intrínseco sentido histórico, su tensión hacia el futuro, su vitalidad y dinamismo. Él representaría, pues, una voluntad de búsqueda de sentido pleno y total, para sí y para el mundo, que mantiene en movimiento la historia y se resiste a aceptar el carácter definitivo de cualquier época y de cualquier supuesto fin de la historia.

Pero, paradójicamente, junto con este impulso de búsqueda de sentido dentro del propio cristianismo se hallan también los gérmenes que conducirán a la época moderna; aquella que se caracteriza por la experiencia de la pérdida de sentido y, consecuentemente, de historicidad. Así, el reconocimiento cristiano del carácter de persona de cada hombre trajo aparejado con el curso de los siglos un cambio en la concepción del trabajo en Europa. Progresivamente el peso agobiante de las labores fue desplazándose de esa cosa sin carácter moral que era el esclavo hacia un ser que tiene en su familia y en sus bienes, por más modestos que estos fuesen y por explotado que él resultase, un carácter en principio libre, y que puede realizar objetivamente esta libertad en el mundo, precisamente a través del trabajo. Esta nueva visión del trabajo, unida al escepticismo respecto al carácter último del saber teórico de la antigüedad, contribuyó a gestar una nueva concepción del conocimiento como algo esencialmente práctico y eficaz, instrumento de liberación de las labores esclavizantes y de dominación de la naturaleza. Tal concepción coincidía con cierta tendencia de la teología cristiana a considerar que el hombre no está en el mundo para contemplarlo, sino para servirse de él y actuar; y convergía con otra tendencia teológica, a saber, aquella que ya no veía en la naturaleza la physis de la que todo proviene y en la cual el hombre mora, sino el reino inanimado de las criaturas, del que el hombre está separado en virtud de su sola relación con Dios. El camino a 
la consideración de la naturaleza como ob-jeto explotable estaba abierto. Al potencial contenido en la nueva relación con el trabajo y la naturaleza se suma, además, la idea de misión y la vocación universal del cristianismo, para quien el pueblo de Dios estaba repartido por el mundo entero. El resultado para Europa fue una fuerza expansionista que, después de las cruzadas, adquiriría dimensiones inéditas con los viajes de descubrimiento, la colonización y la explotación de las riquezas del mundo. Todo ello, sumado a la creciente evolución de las técnicas productivas y de las prácticas comerciales y financieras, conducirá, como afirma Patočka, "al nacimiento de un racionalismo de un tipo totalmente nuevo, el único que nosotros hoy día conocemos, el racionalismo que, queriendo dominar las cosas, es dominado por ellas". ${ }^{23}$ Estamos ante la génesis del racionalismo moderno. Por otra parte las transformaciones ocurridas en el seno del propio movimiento cristiano: el paso de la autonomía eclesiástica al cristianismo laico y, ante todo, la mentalidad de la reforma, que introduce la idea de la consagración individual por la bendición económica, contribuyeron a fomentar el proceso de producción que caracteriza al capitalismo moderno. Éste no tardó en independizarse de su impulso religioso, volverse autónomo y aliarse con el nuevo racionalismo, orientado por esencia hacia la objetividad, separado de todo vínculo con la trascendencia, y provisto de un formalismo matemático que lo vuelve infinitamente eficaz. En ese momento la modernidad había comenzado su reinado.

Pero el esplendor de la modernidad representó también la decadencia del sentido y el surgimiento del nihilismo. En efecto, el suceso y la eficacia sorprendentes de la objetividad científica y de la aplicación de métodos matemáticos en las ciencias naturales terminaron convirtiendo todo ente, incluso el hombre, en un objeto formal, vacío de ser propio, cuantificable y dominable. Este proceso, que niega a la naturaleza y al hombre todo sentido inmanente, y que también niega, en tanto no objetivable, el sentido de cualquier trascendencia, no puede desembocar sino en el nihilismo: en la convicción de que nada absolutamente tiene sentido por sí mismo. La ciencia natural se convierte en nihilismo natural desde el momento en que se reduce a una disciplina facto-lógica que permite manipular hechos, aunque lo que sea en sí misma la naturaleza y el sentido del universo y de las cosas le sea incomprensible e irrelevante. Ella no puede integrar el sentido particular y relativo propio de su eficacia en un régimen de sentido total y pleno, que comprometa todas las dimensiones y esferas de la vida humana, y que impida que los sentidos particulares terminen anudándose con el sinsentido. Por el contrario, su justificación le viene a la ciencia, por así decir, de afuera de sí misma, del insensato, desmedido e injustificado deseo de poder, de confort y de consumo del sujeto y de la sociedad, el cual no es sino 
una manifestación más de ese nihilismo. Parecería, pues, que todo el movimiento de la historia, después de los diferentes impulsos hacia la búsqueda de un sentido pleno de la existencia individual y colectiva, cuyas manifestaciones más importantes, para Patočka, han tenido lugar en la política y en la filosofía metafísica surgida en Grecia y en una religión tan profunda y vital como el cristianismo, desemboca allí mismo donde había comenzado: en el encadenamiento del hombre prehistórico al trabajo y a la satisfacción presente de las necesidades materiales de la vida. El hombre posthistórico-nihilista estaría sujeto al presente en la misma medida que el hombre prehistórico-mítico lo estaba al pasado. Si para este último todo futuro no era sino una reiteración del pasado mítico, para el moderno todo futuro no viene sino a completar este presente definitivo. Ambos parecen estar privados de toda relación con un advenir hacia el cual orientar el conjunto de su existencia, ambos pasan por alto que la realidad es cuestionable y asombrosa, y que requiere la constante búsqueda de sentido de cara ante el sorprendente milagro del ser, y ambos, por ende, carecen de sentido histórico. Parecería, pues, para decirlo en una palabra, que todo el movimiento de la historia hubiera, paradójicamente, conducido a una nueva prehistoria. Sin embargo, advierte Patočka, la situación es aún más compleja. La prehistoria no puede caracterizarse como una negación del sentido. El hombre prehistórico encuentra en el mundo un sentido que, aunque modesto, no crítico, excéntrico por relación al hombre y relacionado con potencias primordiales no es, sin embargo, un sentido parcial y sectorizado. Él puede vivir en paz con los entes y los dioses y no necesita sacrificar a Dios, la naturaleza y, con ellos, posibilidades de vida sensata, conquistadas a lo largo de milenios, a lo que, en última instancia, se revela como lo más cotidiano, vulgar y desprovisto de sentido: el deseo ilimitado de poder y de placer que amenaza colocar al planeta entero al borde de la destrucción.

Vistas las cosas desde esta perspectiva, a historia, de la que habíamos afirmado que sólo era posible como historia de la búsqueda de sentido, pareciera desembocar en la "revelación progresiva del no sentido del universo". 24 El llamado incondicionado que ponía el origen de la historia en algo absolutamente otro y trascendente respecto de la historia misma parece haberse acallado; y la historia, que debería, realizando la infinita variedad y riqueza de un sentido dinámico y abierto, ser el campo en el cual el hombre despliega su pulsión hacia lo divino, se convierte justamente en lo opuesto: en la realización del nihilismo. Es entonces cuando se vuelve necesario volver a hacer oír la voz silente de Dios, promoviendo la infinitud de la vida y del sentido. Es entonces cuando es menester el sacrificio para mantener viva la historia. 


\section{LA FILOSOFÍA DEL SACRIFICIO}

\section{III.1 SACRIFICIO ACTIVO Y SACRIFICIO PASIVO}

De esta encrucijada del sinsentido en la que nos encontramos sólo puede salvarnos, para Patočka, el sacrificio ¿Qué habrá que entender, pues, por sacrificio y cómo puede él ser lo salvífico? Patočka distingue dos modos del sacrificio en la experiencia del hombre contemporáneo: el pasivo y el activo. El pasivo es la suerte que han corrido y corren innúmeros seres humanos cuyas vidas han sido "sacrificadas" a lo largo de los conflictos y de las guerras del siglo XX, a través de los cuales se han liberado las inmensas energías acumuladas por la ciencia, puesta al servicio de la técnica y de la convicción nihilista de que no existe otro valor ni otro sentido que la fuerza. Para los que llevan a los hombres a este tipo de sacrificio las vidas humanas sacrificadas no son un fin, sino un medio, cuyo sacrificio está justificado a la luz de "finalidades superiores" y de "intereses objetivos", a saber, aquellas "finalidades" a las que les conceden valor "objetivo" los "intereses" de aquellos "superiores" que detentan la fuerza y quieren incrementar su poder. Este el modo en que concibe el sacrificio la comprensión técnica del ente, que reduce la vida humana al rango de una fuerza más "capaz de entrar en un juego gigantesco en el que las fuerzas liberadas en medio de procedimientos técnicos se consumen". ${ }^{25}$ Sin embargo, este sacrificio pasivo implica ya un primer grado de revelación de que la civilización contemporánea nihilista va en contra del sentido de la existencia humana y, por ende, de la propia historia del hombre en tanto historia con sentido. Tal revelación radica en el hecho de que la eliminación de vidas humanas en el medio de los conflictos que liberan fuerzas acumuladas sea vivida como sacrificio. Precisamente que, a diferencia del empleo de cualquier otro instrumento, la utilización de la vida humana como recurso sea experimentado como sacrificio "testimonia el hecho de que el ser humano se resiste a ser reducido al rango de ente disponible". ${ }^{26} \mathrm{De}$ allí que la misma experiencia del sacrificio pasivo sea el punto de partida hacia una comprensión del ser diferente de la del "ente disponible" y de la historia como la mera continuación y acrecentamiento de lo Mismo.

Pero existe otro tipo de sacrificio: el activo, a saber, el de aquellos que han sido conmovidos por el sinsentido del mundo contemporáneo y que se sacrifican a sí mismos o su posición social o los beneficios y comodidades de los que gozan, para decirle "no", para oponerse a esta comprensión nihilista que reduce todo ente a fuerza disponible. Esta idea del sacrificio activo es, como el propio Patočka lo indica, de origen religioso y consiste en una "voluntad de

25 F. Karfik, loc. cit., p. 26.

26 Ibid. 
comprometerse, por la humillación y el abatimiento de sí, a una instancia más alta a la que se espera ligarse en virtud de la reciprocidad así engendrada". ${ }^{27}$ A diferencia de la visión técnica, que no reconoce en el ser del ente ninguna diferenciación y que todo lo ve como un instrumento, el sacrificio implica una auténtica distinción de sentido y rango en el orden del ser. Por ello el sacrificio más excelso es el de la vida humana y por ello sólo lo divino merece tal sacrificio. "El sacrificio religioso presupone una diferencia jerárquica entre el ser divino y el ser no divino. El sacrificio por alguna cosa o por alguien sería impensable sin la idea de una diferencia entre el ser del hombre y el ser puramente cósico; sin la idea de una diferencia, en el interior de lo humano, entre las posibilidades de acrecentamiento y de las de disminución de ser". ${ }^{28}$ De allí que nadie se sacrifique por lo que es vulgar e igual a todo lo demás, por alguna cosa indiferente de las otras, sino por lo que es esencialmente diferente, por aquello con lo que debo mantenerme en relación para que mi propia existencia tenga sentido. De allí también que un sacrificio que implique entregar la vida en un sentido absoluto o en el sentido de renunciar a ciertas posibilidades vitales se haga en función de la relación con algo que se considera superior a esas posibilidades y a la mera vida animal misma; se haga, pues, por algo que le da a la vida el sentido que necesita para ser digna de ser vivida. Así concebido, el sacrificio implica, como se dijo anteriormente, una jerarquía ontológica. Cuando los hombres se sacrifican o ven a otros ser inmolados o inmolarse, ellos comprenden que no todo es lo mismo, que hay aquello diferente por lo cual tiene sentido sacrificarse, y que ese sentido es lo que justifica la existencia, en tanto existir es buscar sentido. Para la comprensión técnica la idea del sacrificio activo, la idea de sacrificarse con tal de no consentir ser reducido ni reducir a los demás a un fondo utilizable que no puede decidir el sentido de su propia existencia, es incomprensible e insensata, pues precisamente para ella nada tiene otro destino que convertirse en una fuerza disponible. "Los sacrificios son, así, la presencia persistente de lo que no aparece en los cálculos del mundo técnico". ${ }^{29}$ Ellos, cuando son comprendidos en su sentido activo, manifiestan una transformación en la relación humana con la verdad y el sentido. Quien se sacrifica comprende y da a comprender que el valor de la vida humana como generadora del propio sentido y la propia verdad en el encuentro con los otros y con el mundo es irreductible. Él comprende y da a comprender, en síntesis, que no todo ser es lo mismo, que el hombre no es cosa, de cuyo sentido se pueda disponer para alimentar el juego de fuerzas. En esa

27 Jan Patočka, Liberté et sacrifice. Ecrits Politiques, trad (francesa) de E. Abrams Grenoble: Editions Jérôme Millon, 1990, p. 271. Sigla: $L S$.

28 LS, p. 272.

29 LS, p. 273. 
comprensión vivida, que no implica un discurso de tipo teórico, ni presupone ninguna afirmación determinada, ni, tampoco, intenta imponer ninguna otra cosmovisión diferente de la comprensión técnica del ser del ente, sino que se limita a la negación a subsumirse en el sistema de fuerzas que esa misma comprensión impone, radica el sentido último del sacrificio como "superación de la comprensión técnica del ser". ${ }^{30}$ Este sacrificio activo, a diferencia del pasivo, no es ningún sacrificio "positivo". No es un sacrificio para conseguir realizar un determinado interés de las fuerzas que dominan el mundo objetivo y que Patočka, en otro de sus ensayos heréticos, denomina "las fuerzas del día".31 En esencia esta forma superior del sacrificio no afirma nada ni se afana por el logro de ningún contenido positivo, sino que, en todo caso, aquello que quiere lograr se enmarca, en su sentido más profundo, dentro de una negación. "La acción, debe, por el contrario, comprenderse bajo la sola perspectiva de la protesta, como un no que no se dirige a estados de hechos singulares y concretos, sino -en el fondo- al modo de comprensión que los sostiene." 32 El sacrificarse por alguna cosa se transforma en un sacrificio por lo que no es ninguna cosa ni nada cósico. Adquiere el sentido de un comprender y dar a comprender, por la vía de la negación del nihilismo, la relación auténtica del hombre con su existencia, con el sentido y con la verdad, esto es, con aquello que lo hace propiamente humano. En tanto tal, el sacrifico activo no es un sacrificio por alguien determinado, sino que lo es por la humanidad toda.

\section{III.2 EL SACRIFICIO, LA HISTORIA Y LO DIVINO}

¿Cuál es, pues, la función histórica del sacrificio y en qué medida esa función adquiere un rango o una dimensión religiosa? La determinación del sacrificio activo y del pasivo nos pone en condiciones de bosquejar a grandes rasgos una respuesta a esta pregunta crucial, en cuanto de la función del sacrificio depende, en gran medida, la renovación de la historia o el retorno definitivo de la prehistoria. Ante todo hay que insistir que, para Patočka, la historia es el producto y el reflejo de la vitalidad del espíritu humano, constantemente llamado a buscar y postular sentido. Lo que sostiene la movilidad histórica es, pues, el principio de creatividad del espíritu, en la medida en que el sentido o la comprensión fundamental del mundo de una época dada acaece a partir de la comprensión que el espíritu gesta de su propio "ser-en-el mundo" y, consecuentemente, a partir del modo en que el hombre descubre las cosas, la naturaleza y la sociedad. Y como el espíritu humano -en tanto existe en el presente pro-yectando hacia el 
futuro las posibilidades heredadas del pasado- es histórico, la comprensión del ser y del ente que él gesta también lo es.

Ahora bien, cuando el espíritu humano responde negativamente al llamado incondicionado a postular y generar sentido a partir de la proyección de un advenir total surgido de su encuentro con el mundo y con los otros, cuando -como sucede en la época de la comprensión técnica del ser-el hombre está convencido de que nada tiene sentido por sí mismo, sino como medio para satisfacer del modo más sofisticado posible sus necesidades básicas y sus apetencias de poder, cuando, además, el hombre, preso de sus propios deseos desmedidos de control del ente, se autoconvence de que esta situación es definitiva, entonces ocurren dos cosas: el hombre se niega a sí mismo, niega lo que tiene propiamente de humano, y la historia revierte en prehistoria. En ese momento se vuelve absolutamente imprescindible comprender. Es preciso comprender que el tipo de vida que se nos impone como única sensata, a saber, cumplir nuestra función dentro del engranaje de producción de fuerzas y bienes de consumo, nos rebaja al nivel de cosas. Es necesario comprender que el sacrificio (pasivo) de múltiples vidas y culturas, como así también de la naturaleza en beneficio del sistema de producción y acumulación de fuerzas es inaceptable, porque aquello por lo que se sacrifica lo sacrificado no es digno de sacrificio alguno ni está en el mismo rango de ser que la vida sacrificada. Es determinante, en síntesis, comprender que las vidas entregadas son precisamente sacrificadas (he aquí el sentido positivo del sacrificio pasivo). Pero comprender tal cosa no implica tan sólo realizar un discurso teórico más entre los innúmeros ya existentes acerca de la crisis de la civilización contemporánea y del mundo postmoderno, sino que la comprensión tiene que ser una comprensión vivida y activa. Pero tal comprensión sólo es posible cuando le decimos "no" a los preceptos que rigen la civilización nihilista, cuando renunciamos a las ventajas y posibilidades que ella nos brinda, cuando estamos dispuestos a sacrificar lo que fuere, incluso la propia vida, con tal de que el hombre no sea considerado una cosa disponible más de la que valerse para incrementar el dominio sobre las cosas. Es allí, precisamente, cuando se vuelve necesario el sacrificio activo, porque él es el testimonio de esa comprensión vivida. Para Patočka el paradigma de esta forma de sacrificio se encuentra en la pregunta de Cristo dispuesto al martirio por la humanidad toda: “¿Señor por qué me has abandonado?". En la pregunta, constata Patočka, se halla implícita la respuesta: "Qué es lo que hubiera arribado si tú no me hubieras abandonado. Nada. Sólo puede llegar algo nuevo si tú me abandonas. El que se sacrifica debe ir hasta el límite, precisamente porque no hay nada ahí, ninguna cosa a la que él pueda todavía adherirse". ${ }^{33}$ Es necesario, entonces, darse cuenta de que todo nos ha abandonado y desprendernos de 
todo eso que nos ha abandonado, para que todo pueda acaecer bajo otra luz y podamos así recomenzar con algo nuevo.

Pero si el sacrificio es el motor de la historia es, por ello mismo también, aquello que -hoy más que nunca- vuelve a restablecer nuestro lazo con el llamado incondicionado y eterno a realizar, a través de la historia, la infinita y múltiple riqueza del ser. Así comprendido, el sacrificio nos revincula una vez más con la eternidad y, en tanto tal, representa nuestro vínculo religioso por excelencia con lo divino. Lo divino es un término peligroso "que puede hacer el juego a aquellos que nos reprochan no hacer filosofía, sino teología disfrazada, un reemplazo de la religión". 34 Pero el acceso que abre Patočka a la relación religiosa por medio de la vitalidad de la historia y del sacrificio que, en los momentos críticos, nos religa con lo divino que nos llama a ser y a hacer historia, es filosófico, no teológico y no representa ningún sustituto de la religión. Con lo divino no se refiere Patočka a ninguna revelación positiva determinada, sino "simplemente a aquello que domina todo, que está por debajo de todo"35 y que traspasa el universo entero como impulso a realizar su infinita riqueza. En tal sentido, estamos en pleno derecho de utilizar filosóficamente el término "divino", sin por ello determinarlo ni teológica ni ontológicamente. Lo divino, así entendido, no es el Universo - no hay aquí ningún panteísmo vitalista- sino, como el propio Patočka lo señala, el Misterio, ${ }^{36}$ que, sin dejar de ser él mismo, se manifiesta a través del impulso a realizar la inagotable riqueza del ser. Cada época histórica, en tanto reflejo de una gran aspiración de sentido humana, es una "expresión especifica" 37 de esa riqueza. Y el hecho mismo de que lo sea, esto es, de que ninguna configuración de sentido ni ninguna época histórica logre captar o comprender definitivamente el universo, de que ninguna clave sea suficiente para abrirlo, es el más claro testimonio "no de que él sería desesperadamente absurdo y, en este sentido, pobre, sino, antes bien, de su infinita riqueza", ${ }^{38}$ y del carácter inescrutable y trascendente del Misterio que, a través suyo, se expresa. Si esto es así, entonces relacionarse con el Misterio que se liga a nosotros llamándonos a ser $\mathrm{o}$, dicho en otros términos, acceder a una genuina relación religiosa, no consiste en ninguna doctrina determinada ni definitiva, ni en la posesión de ninguna verdad revelada. Acceder a una genuina relación religiosa es ser en y para el acontecimiento histórico, dinámico y siempre renovado de des-cubrimiento del ser y de la vida en su infinita riqueza. Tal cosa, sin embargo, no es sino "existir en la verdad".

$34 \quad L S$, p. 313.

35 LS, p. 313.

36 Cf. $L S$, p. 238.

$37 \quad L S$, p. 238.

38 LS, p. 238. 
La vida en la verdad, la vida verdaderamente religiosa, no significa la posesión de la certeza bajo la forma de juicios válidos o representaciones concordantes con las cosas del mundo, como si la verdad fuese un objeto ideal externo al hombre. Existir en la verdad es estar constantemente buscando y proyectando los infinitos horizontes de sentido que hacen posible toda comprensión y toda verdad, y que, a la par, testimonian la infinita riqueza del Misterio. Mas ello implica, inicialmente, asumir la existencia "interesar-me, ser preocupado por mi posibilidad esencial, es decir, no ser indiferente a mi manera de ser y a lo que yo soy". ${ }^{39}$ A una con ello, implica también, si la existencia como apertura al ser ha de ser llevada hasta sus extremos, ir más allá de las metas mezquinas de la cotidianidad y dejarme conmover por el todo del mundo y por la dignidad y diversidad de la vida humana que, a cada día, renueva ese mismo mundo. Existir en la verdad no siempre es cosa fácil. A veces cuesta el sacrificio de la propia vida.

Ángel E. Garrido-Maturano pertenece al CONICET - Universidad Católica de Santa Fe (Argentina).

\section{Publicaciones recientes:}

2006: Sobre el abismo. La angustia en la filosofia contemporánea, Buenos Aires: Adriana Hidalgo, pp. 352. ISBN 987-1156-52-9.

2010: Los tiempos del tiempo. Ensayo acerca del sentido filosófico, científico y religioso del tiempo, Buenos Aires: Biblos, pp. 270. ISBN 978-950-786-808-5.

Línea de investigación:

Fenomenología

Dirección electrónica:

hieloypuna@hotmail.com

39 Jan Patočka, Le monde naturel et le mouvement de l'existence humaine, trad. (francesa) de H. Declève, Dordrecht/Boston/Londres: Kluwer Academic Publisher, 1988, p. 262. 